\title{
E1 Rif y el Protectorado Español
}

Alí Mohamed Laarbi

Investigador

LA DIFICULTAD DB DELIMITAR EL CONCEPTO DE "EL RIF" ANTES DEL PROTWCTORADO EBPAÑOL

En las obras especializadas en cuestiones del Norte de Africa, al Rif se le considera algunas veces como una región desvinculada de lo que es el reino de Marruecos, por haberse librado durante distintas fases de su historia a la hegemonía del Maghzen.

Es sumamente necesario determinar los territorios que abarca, pues hasta finales del siglo XIX no hubo unanimidad de criterio respecto a esta cuestión.

El sentido que se le otorga al vocablo Rif varía según los países denominados árabes. En Marruecos se usa dicho vocablo principalmente para señalar la región bordeada por el Mediterráneo. Así pues la palabra Rif en Marruecos se emplea para referirse a las cábilas que habitan a orillas del mar, pero no todas ellas forman parte del verdadero Rif. Dicha palabra constituye estrictamente la expresión geográfica de una región revistiendo connotaciones políticas cuando se quiere referir a ciertas tribus ribereñas del Mediterráneo, es decir, que este vocablo que encierra una expresión geográfica ha tomado un sentido político para designar con él ciertas tribus ribereñas del Mediterráneo.

Los límites del Rif han variado en el transcurso de su historia siguiendo el desplazamiento de las cábilas.

Podemos decir con Michaux Bellaire que la palabra Rif no es el nombre de una tribu, ni de un pueblo: con ella se designa el borde o mar- 
gen de una cosa. En un campamento, por ejemplo indica las tiendas de campaña instaladas en la faja exterior que circunvala al campamento, y asi se dice "errif" de la Mehalla (1).

El empleo de este vocablo en el sentido militar data de la época, en la que, los puertos de la costa mediterránea de Marruecos eran objetivos de los ataques españoles, de aquí que la palabra pudiera muy bien haber sido tomada en el sentido de la línea de defensa, baluarte del islam contra la cristiandad (2).

Delbrel apunta que los límites de los mahal, o campamentos militares del Maghzen, son llamados rif, y así podría suceder con la región rifeña, la cual, en los siglos pasados y en las épocas de lucha que siguieron a la expulsión de los moros de España, el litoral Norte marroquí era la línea directa del contacto del musulmán con el cristiano invasor, de donde el calificativo del rif - límite - pudo dársele, perpetuándose hasta nuestros días (3).

¿En qué época, pues,6e empleó por primera vez tal vocablo?

Según Michaux Bellaire fue a partir del reinado de los Beni-Merín para designar con él, determinada región del Norte de Marruecos, tal palabra se encuentra empleada en un manuscrito del siglo XIV de Abdelhak El Badissi, el autor denomina rif a toda la región que se extiende desde Ceuta a Tremecén (4).

Sin embargo, Eduardo Maldonado recalca que es en el conocido Ajbar Machmua tan explotado para explicar los comienzos de la invasión árabe en España, cuyo autor anónimo debió vivir en el siglo XI, donde parece deducirse que el empleo del vocablo "Rif" da idea de litoral para aprovisionamiento, idea que también tiene sentido militar. Añade Maldonado que dicho vocablo tiene su justificación, si no como baluarte del islam contra las incursiones de los cristianos españoles, cuyas flotas guerreras eran casi inexistentes (salvo las gallegas), sí como secuela del horroroso saqueo que sufrió la capital de Nekor a manos de los normandos, que, rechazados en Sevilla, desembarcaron en el Rif (5).

A través del transcurso de la historia, el calificativo rif llegó a definir una decisión politica administrativa del sultanato de $\mathrm{Fez}$, sin que eso tenga como soporte límites geográficos impuestos o afinidades étnicas declaradas.

Con el protectorado español el término rif correspondía sólo a una decisión filológica, por la cual quedaban reunidas, bajo una misma 
denominación, cábilas de distintos orígenes que han conservado más o menos puro el habla "amazigh" diferenciándose de otras cábilas de igual orígen y antiguamente consideradas como rifeñas, que por efecto de varios factores han perdido completamente el uso del idioma "amazigh" (6).

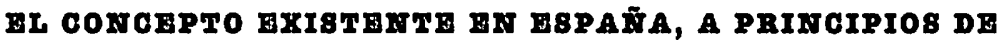 8IGLO, DE L08 RIFĒ̃o8 Y DEL AIF}

Cuando fue nombrado el doctor Ruiz Albéniz por el sindicato español de las Minas del Rif, médico de las minas de Beni-Bu-Ifrur (Segangan) quiso orientarse, antes de emprender su viaje, sobre qué era el Rif. Respecto a esto nos dice Ruiz Abéniz: "No pude hallar un libro español que se ocupase de Africa, consulté varios franceses, entre ellos con verdadera avidez L' Islam, del conde Henry de Castries; Voyages au Maroc, de Segonzac, y Le Maroc d'aujourdhui, de Eugène Aubin.

Estos libros me dieron noticias sobre el pueblo magrebino, mas no se hablaba nunca del Rif, y mucho menos de Beni-Bu-Ifrur", y prosigue el autor: "Mis pesquisas verbales no tuvieron mejor fortuna, varios militares que habían pertenecido a la guarnición de Melilla nada me pudieron decir, porque los soldados españoles no podían salir de los límites de la zona fuerte y los moros mercaderes de Melilla no eran muy pródigos en eso de dar referencias del interior, todos me hablaban pintándomelos como semi-salvajes y seres incivilizados; del Rif de un país mísero, virgen de toda ley y cultura; de Melilla como una cárcel custodiada por soldados, y de Africa sólo sabíamos que había que seguir con el grito inveterado de guerra al infiel" (7). Y se pregunta el autor ¿̨cómo explicar ese total desconocimiento nuestro, dado que España es el país europeo que puede alegar mayores, más antiguos y más sólidos derechos respecto a Marruecos?.

El Rif era completamente desconocido, España llevaba tres siglos de dominación en Melilla y durante ese tiempo muy pocos habían intentado atravesar los límites de la plaza de Melilla para conocer el mundo rifeño, mientras que los rifeños entraban a diario en Melilla a vender los artículos de su producción.

Sobre la venta ambulante en Melilla, nos cuenta un militar en los primeros días de su estancia en la ciudad, que lo que le llamó la atención fue el personal abigarrado y multiforme que transita por las calles con sus extrañas vestimentas. "A las diez en punto de la mañana, un marinero 
de la Compañía de Mar, permite la entrada a los moros, que invaden las calles con su vocerío especial, empeñándose en vender a la fuerza" (8).

Respecto al instinto comercial del rifeño nos dice el "moro vizcaíno": "Que los rifeños tienen un instinto comercial muy grande, grande debe ser cuando hacen el contrabando de ganado, que no es cosa muy fácil" (9).

En España se tenía una remota idea de lo que era el Rif, y si se ha concedido algún tiempo para conocerlo, fue para averiguar cuántos habitantes tiene, de cuántos guerreros dispone, y de qué color son sus chilabas y jaiques (10).

¿Qué se conocía de los rifeños pues?

Si se conocía algo de ellos fue a través de terceros, y de lo que se comentaba de ellos. El "moro vizcaíno" hablando de los rifeños nos dice que tienen aquí y allá fama de ser malos, muy malos, y lo son en verdad (11).

Rafael Guerrero se apoya en las afirmaciones de Amicis que decía para describir al rifeño:

Ya sé, por fin, quiénes son estos hombres rojos, mal encarados, que cuando pasan a mi lado por las calles apartadas, me echan una mirada en que parece que centellea la tentación del homicidio. Son los rifeños bereberes de raza, que no tienen más ley que la espingarda, que no tienen caíd ni magistrado; los piratas audaces, los bandidos sanguinarios, los eternos rebeldes que pueblan las montañas desde las costas desde Tetuán a la frontera argelina, que no han podido dominar los cañones de los buques europeos, ni los ejércitos del sultán; los habitantes en fin, del famoso Rif (...) aquellos de quienes se cuentan toda clase de leyendas pavorosas, $y$ de cuyos territorios hablan los pueblos vecinos vagamente, como de un país lejano e inaccesible (...), comparados con estos los árabes más salvajes me parecen amigos de la infancia. (12).

Tal desconocimiento llevó a poner en evidencia las diferencias entre el protector y el protegido y a valorizar estas diferencias en beneficio 
del protector y en detrimento del protegido y llevar esas diferencias a lo absoluto, tal era el caso de Silvestre, que tenía un concepto especial del rifeño tal que al tratarlo se alzó en su espíritu un sentimiento de infinito menosprecio, que según él convenía tratar "con la punta de la bota" (13).

Y no era sólo Silvestre quien así procedía, sino también parte de su estado mayor; el periodista Juan Guixe recuerda que un militar decía en pleno Zoco el Had, (Nador), el mismo día de la visita del señor Sierva, después de haber reunido a trescientos rifeños en la explanada del zoco para rendir saludo al señor Sierva, que el mejor modo de resolver el problema de Marruecos lo iniciaría cortando la cabeza a los ahí congregados (14).

Consecuencia de tal mentalidad, que el protectorado había perdido el contacto con las cábilas y que éstas menospreciadas acrecentaban sus ansias de venganza al español, al no comprender la mentalidad de un pueblo supone el no captar su carácter normal y dar paso a la guerra colonial que implica inevitablemente el choque entre las culturas.

España había elegido una vez más la solución más radical: la guerra, suprimir la materia humana.

\section{AUSENCIA DE POLITICA GOLONIAI}

A consecuencia del tratado de 1912, se le concedió a España una zona en el Norte de Africa de unos $22.000 \mathrm{Km}^{2}$.

La acción colonial de Francia, era más fácil, tenía el pretexto de proteger al Sultán.

España tenía que fabricar a quién proteger. En el tratado se estipulaba que en la zona Norte se instalaría un delegado del Sultán, que con la ayuda de España impondrían el protectorado:

En el Marruecos francés se encontraban asentadas las cábilas apegadas a la hegemonía del Sultán, en cambio en el Norte de Marruecos la mayoría de las cábilas disfrutaban imponiendo sus instituciones ancestrales, con este escollo tropezó el protectorado español.

Desde el primer momento las cábilas rifeñas se mostraban indiferentes a las órdenes de tal invención, consecuencia de la puesta en marcha del tal Jalifa carente de prestigio fue la de sustituir su desacreditado poder por la máquina colonial española, pero España no tenía otro aprendizaje en el sentido de protectorado que la historia colonial en las Antillas y las primeras campañas en el Rif oriental, de ahí que desde el 
principio la tendencia política dominante se orientase a las acciones bélicas, olvidándose del estudio sociológico basado en la observación y en la comprensión de la forma de ser de los rifeños que debe encararse atendiendo a los valores que imaginamos que los rifeños asignan a las cosas, atendiendo a las fórmulas que ellos usan para definir lo que sucede.

El desconocimiento de la realidad rifeña llevó a los militares a optar por el dominio armado.

Cándido Lobera dice que la esencia de la actuación española ha de ser el reconocimiento de que somos los más fuertes en todos los órdenes, lo mismo en tiempos de los cartagineses que en nuestros días, para llegar a una situación estable fue preciso que el palo precediera al pan (15).

El segundo escollo que se presentó a la acción española fue la ausencia de jefes de prestigio entre las cábilas, si en la región del Sur marroquí, donde hay grandes caídes es cosa fácil absorberlos en el proyecto colonial mediante dinero, pues la sumisión del caíd lleva consigo la de la región, en donde ejerce autoridad. En el Rif no hay grandes caídes, cada cabeza de familia es un jefe independiente y por tanto resulta cosa imposible aunar voluntades. (16).

La formación socio-política de los rifeños, su división en familias solidarias entre ellas, la indivisión de la propiedad y sus instituciones concuerdan hacia la consolidación del grupo y a extender la solidaridad entre los miembros de una colectividad, tales son las circunstancias especialísimas del país (17).

Tercer y gran tropiezo que se encontró el protectorado español desarrollando su acción radica en el desconocimiento del territorio y de las instituciones. ¿Es que esto no se pudo hacer? Sí se pudo hacer política en vez de enclaustrarse en plazas y posiciones y se entendió dice Ruiz Albéniz: "que proteger es dominar efectivamente, con armas, con blocaos, con la insensata organización de política indígena que empieza por imponer a las cábilas jefes que carecen de todo prestigio" (18).

La ignorancia, el atávico sentimiento de repugnancia hacia el moro, el inextinguible deseo de conquista inherente a toda guerra colonial implica inevitablemente el choque entre dos culturas y la intromisión de pasiones ciegas, violentas e insidiosas, la falta de preparación de los que piensan y mandan y de los que obedecen y ejecutan, el afán de hacerlo todo 
por el procedimiento de improvisación. Pues bien, esta es la mentalidad que se impuso para ejercer el supuesto derecho de proteger.

El entusiasmo loco de muchos militares recién llegados a Melilla; la inmadurez política, la precipitación de los jefes, el enardecimiento bélico de los que tenían mandos llevaron a extremos desoladores.

Los soldados recién llegados de España, combatían en desorden con intranquilidad, más a modo de víctima que mata por no morir, que de espíritu tranquilo que combate con ideales grandes (19).

He aquí una carta que envía un soldado a su novia que refleja la situación psicológica del soldado español y de la incultura en que se hallaba inmerso.

Dice el soldado Quico:

Una de las vese le tocó a mi compañia $i$ a aurxiliá a nuestros ermanos, que se los comian bibo los moros $y$ aqui tiene a tu Quico metio en faena de verda. Me apreté er correaje, me apreté la chaquetiya, me apreté, me apreté las polainas... tó me lo apreté, porque tó le resurta a uno grande cuando le dan una mala notisia.

Jalá pa lante en formación y sin dejá de oi tiros. Ya comensaba a clareá y por la parte der Gurugú, que es un monte que no se acaba nunca de arto que es, no sé si de los moros o de los cristianos, porque uno no se da cuenta de ná, y aqui muere er que está bautisao lo mismo que er que no lo está.

De pronto oigo desi ar capitán-jabrirse en guerrilla $y$ pa lante disparando! - y comensamo a sunbá tito dé donde dé. Las balas sirbaban; yo las oia pasá poensima e mi confiao en que aquellas no me daban ya. Ma cordé de ti, Josefilla. Yo crei que te queaba sin nobio. Er capitán, que es más baliente que un jabato, no asia más que gritá - iA eyos; balientes! - y en esto cayo un compañero. Cuando lo vi cae me entró coraje, y arremeti palante, $y$ casi me queé solo. Miré a un lao, en una regüerta, y bi un moro tendio muerto... Más bale que no lo ubiera bisto: me queé sin salyva, con la boca seca. Llo no é 
bisto en mi bia un moro más largo: tenía lo meno tres metros y la cabesa pelá, como una seboya. Estos tios se alargan al mori así como nosotros nos encogemo. Estos moros largos serán los moros der Gurugú, que está en consonancia con er monte. Doce moros destos, uno encima de otro, bendrá a tene la artura de la Girarda, y me queo corto. Er capitán me riñe, los compañeros me llaman, los enemigos juian, pero... yo no me atrevia a separarme der moro muerto: me paresia que se iba á lebantá, y que me iba á cogé por la soreja (...) Metí er cuchillo en er mause pa matá otra bes á aquel moro muerto si se llegaba á lebantá. Cuando me separé de allí no así más que gorbe la cara; me parecia que benia detrás de mi. Ya se llo que los muertos no se lebantan, manque se le resen diez oraciones $y$ le canten sincuenta responso; pero... la berdá, yo le miraba y me paresia que guiñaba el ojo disquierdo, $y$ con er puño serrao mamenasaba. $Y$ gorvimos a Melilla, $y$ er tio aqui (...) se me parese de cuando en cuando. Yo creo que me boi a poné malo y me ban á mandá á un ospitá por loco. Por toas partes veo er puño serrao de aquel moro muerto que paresia amenasarme (20).

Si la fórmula propuesta por Lyautey, como base y firme apoyo de toda la acción colonial se concentraba en la unidad de planes y dirección y la continuidad en el esfuerzo, hizo que hasta 1922 Francia sostuviera, con leve interrupción, durante 12 años a Lyautey en la Residencia de su protectorado y con él estaban los mismos generales, jefes y oficiales, en cambio en España cambió cinco veces de Alto Comisario (Alfáu, Marina, Jordana, Berenguer y Burguete) (21).

La falta de preparación de los que ejercían el mando en una región que carecía de cartografía, y el interior de la zona constituía un misterio por conocer; la falta de criterio fijo, de planes concretos de actuación claros; la carencia de una política colonial específica indujo que España hiciera política circunstancial. Ello conducía, a veces, a la política militar 
de conquista, otras a la contemporización de los rebeldes, otras a la de apoyo al Maghzen (22).

LA ORGAUIZACION POLITICO-ADMINISTRATIVA DURANTY BI PHOTRGTORADO IHN BL RIF

Muy oportunamente se ha dicho que Marruecos era una expresión geográfica más que una expresión política.

Toda la historia de Marruecos se basa en una ininterrumpida lucha entre el Maghzen y las cábilas independientes, cuyos límites siempre inciertos, se acrecientan o reducen con relación directa al prestigio religioso y al poder militar del Sultán (23).

La ocupación efectiva del territorio por la acción colonial permitió la existencia del caíd, quien basandose en el apoyo que le otorgan las autoridades protectoras, queda asegurado contra cualquier eventual reacción armada de sus administradores.

En el concepto maghzeniano del caidato, que es el de favorecerse de la situación creada para esquilmar a las cabilas, está todavía presente en el espíritu de los cabileños, y el caíd asegurado de la solidez de su situación por el apoyo del gobierno protector se transforma en autócrata (24).

La aplicación sistemática de una organización a base de autoridades gubernativas (caídes y jalifas), apoyadas por las judiciales cadíes y adules provocaron una arabización más intensa de las poblaciones rifeñas, a las cuales, en lugar de sus instituciones democráticas se les ha impuesto una autoridad autocrática, sustituyendo también el derecho consuetudinario aplicado por la asamblea de los notables por el derecho musulmán, sobre el cual se basan los fallos del cadí.

El intento legislativo del protectorado no se encaminó a dar un cauce en que se desenvolviera la actividad de la yemáa, dándole estado oficial, y reconocer su personalidad, en lugar de ignorarla, cuando el Maghzen resulta encastillado en un medio hostil por incomprensión.

Las consecuencias de imponer el patrón árabe en la organización tribal según Blanco Izaga ha sido un error político inicial, de incalculables consecuencias y el principal de los varios cometidos, debido, sin duda, a no haber sabido diferenciar a tiempo idioma y religión de raza y nación (26). Ello es consecuencia de nuestro espíritu improvisador y anárquico, tan cómodo y provechoso que nos condujo, merma tras merma, a esta cari- 
catura de imperio, trágica herencia, no imputable a esta generación que supo contenerlo y ampliarlo, ni a las virtudes cuyo derroche nadie se permitió dudar, y sí a la mala orientación, falta de plan, estudio de nuestros intereses exteriores, oposición de aventuras y peor organización de nuestras empresas exteriores, entre otras causas (27).

\section{IA POLITICA EDUCATIVA Y LINGÜISTICA}

El sistema de enseñanza implantado por el protectorado mediante el despliegue de mecanismos específicos cumplió la función que había ejercido la enseñanza tradicional, asumiendo sus funciones, ideológica, práctica y política, legitimando las instituciones del Maghzen y manteniendo el orden establecido, reforzando la vertiente simbólica mediante la educación y respetando las materias de fuerte contenido religioso que sustentaban el sistema mítico-ritual.

Los programas y materias fueron adoptados y acoplados a la visión general de la ideología dominante, manteniéndola y reproduciéndola con el fin de implantar una mentalidad acorde a lo establecido.

El lenguaje es el medio más importante de comunicación, constituye la más indispensable entre las condiciones de existencia de todo grupo social. En este sentido, se convierte en uno de los valores más significativos del individuo, careciendo de un lenguaje común, las personas permanecen mútuamente extrañas, no pueden poner de manifiesto el mundo de sus significados valores-normas (28).

La adopción del árabe como idioma oficial implica una decisión jurídico-político-ideológica tendente a la eliminación implícita de la lengua tamazigh, y en apoyo de aquella considerada como nacional por el Maghzen y el protectorado español sin basarse en el criterio de territorialidad consistente en limitar ciertas regiones definidas a beneficiarse de la educación de su propia lengua.

Luis Pérez Lozano considera que el protectorado tuvo delante dos zonas netamente diferenciadas, la berberófona y la arabófona, sin embargo, la administración española favoreció las regiones arabófonas, marginando las otras, que políticamente quiere decir una actitud al soporte, al centro político-administración.

Si entre los diversos mecanismos de eliminación en que está basada la enseñanza figura como fundamental el de la lengua, hay pues 
una relación recíproca entre el saber de una lengua y el éxito escolar. El fracaso escolar del alumno rifeño, era inminente dada la relación directa entre el éxito escolar y la posesión de una lengua (29).

\section{DHSPUES DIL PROTECTORADO}

En 1956 España cedió el control del protectorado al Maghzen. Aquella cesión fomentaba problemas de ámbito administrativo y político. Los rifeños se sintieron frustrados por el cambio que se operó sin contar con ellos y por el cambio que se efectuó en ciertos usos oficiales a los que se habían acostumbrado durante el protectorado. En vez de la administración española, la lengua española y la moneda del país protector, los rifeños se encontraron con un nuevo protectorado que redactaba los asuntos administrativos en francés, acaparando y controlando el poder efectivo. Los rifeños excluidos del nuevo gobierno marroquí se sublevaron y se vieron aplastados bajo las bombas de la aviación de las fuerzas reales.

Hoy el Rif continúa siendo una tierra sin explotar, el porcentaje de natalidad es elevado y el desempleo general y la emigración laboral hacia Europa occidental se ha incrementado. 
1. BELLAIRE, M.: Apuntes para la historia del Rif. Texto mecanografiado, p. 6.

2. Ibidem, p. 8.

3. DELBREL, G.: Geografia general de la provincia del Rif, Melilla imprenta "El Telegrama del Rif", 1911, p. 19.

4. BELLAIRE, M.: Apuntes.... p. 9-10.

5. MALDONADO, E.: "Algunas noticias sobre el Rif de la edad media", Revista del ejército, diciembre, 1948.

6. GHIRELLI, A.: El norte de Marruecos; contribución al estudio de la zona del Protectorado Español en Marruecos Septentrional, Artes Gráficas, Melilla, 1926, p. 170.

7. RUIZ ALBENIZ, V.: El Rif en paz, la guerra del hif. El pleito internacional. Imprenta de Juan Fuego, Madrid, 1912, pp. 12-13.

8. CUEVAS, T. F. de: Recuerdos de mi estancia en Melilla, tip de "E] Telegrama del Rif". Melilla, 1906, pp. 39-41.

9. MLRCA, J. M ${ }^{a}$ de: Recuerdos Marroquies del Maro vizcaíno, imprenta de Miguel de Larumbe; Bilbao, 1868, p. 227.

10. URQLIJO, F. de: La campaña del Rif en 1909, librería de Pueyo, Madrid. p. 32.

11. MURGA, J. Ma de: Recuerdos Marroquies..., p. 227.

12. GUERRERO, R.: Crónica de la Guerra del Rif: $3^{\text {a }}$ edición, M. Maucci, editor, Barcelona, 1895.

13. RUIZ ALBENIZ, V.: El Riff, imprenta de Juan Pueyo, Madrid, 1912, p. 206.

14. GUIXE, J.: El Rif en sombra, sin casa de edición, 1921, p. 163-164.

15. LOBERA, C.: "Política rifeña del protectorado": Serie de artículos aparecidos en El Telegrama del Rif, 1925.
16. L.OBERA, C.: Artículo aparacedido en El Telegrama del Rif, 1921, segundo semestre jueves 29 de septiembre.

17. LOBERA, C.: "Política y Administración en el Rif ${ }^{n}$. El Telegrama del Rif, viernes 7 de octubre $1921,2^{\circ}$ semestre.

18. RUIZ ALBENIZ, V.: Ecce homo Biblioteca nueva, Madrid. 1922, p. 35-40.

19. RUIZ ALBENIZ, V.: La verdad de la guerra, Establecimiento Tipográfico, 1909, p. 59.

20. RODRIGLEZ LA ORDEN, J.: Las cartas de los soldados sevillanos, imprenta de Rafael, 1921 , p. 22.

21. RUIZ ALBENIZ, V.: La verdad de la guerra..., p. 17-89.

22. Idem.

23. SANGRONIZ, J. A.: Marruecos, sus condiciones fisicas, sus habitantes y las instituciones indigenas, sucesores de Rivadeneyra. Madrid, 1921, p. 273-74.

24. GHIRELLI, A.: Notas sobre la islamización y arabización de las poblaciones del Norte de Marruecos, texto mecanografiado, 1927, p. 123.

25. Ibidem, p. 124.

26. BI.ANCO IZAGA. E.: La técnica en servicio exterior de Estado, Delegación de Asuntos Indígenos; abril 1941, p. 33.

27. Ibidem, p. 34 .

28. SOROKIN, D. A.: Sociedad, cultura y personalidad, $3^{a}$ edición, Ed. Aguilar, Madrid 1973. p. 318-319.

29. MOHAMED LAARBI: A.: "Algunos aspectos de la enseñanza española en el Norte de Marruecos", Revista Trápana, n" 3-4 Melilla; p. 89-94. 